\title{
Meta-Analysis: Culturally Sensitive Education and Mammography Uptake of Minority Women
}

\author{
Mabel E. Caban and Beverley Adams-Huet \\ Department of Physical Medicine \& Rehabilitation \\ Department of Clinical Sciences and Internal Medicine \\ UT Southwestern Medical Center \\ Dallas, Texas, \\ USA
}

\section{Introduction}

Women from minority groups live at a disproportionately higher risk of chronic illnesses and cancer increasing their morbidity and mortality.(Newman, 2010) The shocking disproportion could be explained by the genetic makeup, family history, behavioral choices of food and low physical activity. Our behavior about cancer and breast cancer prevention depends on our cultural background because the social environment and culture determine the values of the patient and the provider.(Dein, 2004) Individual and access issues reduces the likelihood of obtaining screening mammography particularly among minority women, for instance, lack of physician's recommendation, not having a regular provider and lack of health insurance. Factors associated with increasing the risk of not obtaining mammography screening include a disadvantaged background, low socioeconomic class, low education, smoking, older age and lack of physician access. (Curtis, Quale, Haggstrom, \& SmithBindman, 2008) Minority women often have a disadvantaged background. SEER data 19862001 demonstrated lower screening mammography rates for various minority groups compared to white women: $50.6 \%$ for non-Hispanic whites, $40.5 \%$ for African-American, $34.7 \%$ for Asian-American, $36.3 \%$ for Hispanic, and $12.5 \%$ for Native-American women.(Kagay, Quale, \& Smith-Bindman, 2006) Mammography use varies by race and ethnicity of the women.

Numerous interventions have been investigated to increase mammography use. Vernon reported that reminder-only studies would predict mammography uptake when compared to educational interventions and counseling, although reminder-only studies were not more effective than education and counseling.(Vernon, McQueen, Tiro, \& del Junco, 2010) Other authors have reported the importance of measuring informed decision making from interventions communicating a health risk.(Fox, 2006) Mandelblatt and Yarbroff studied that provider interventions effectively increase mammography uptake.(Mandelblatt \& Yabroff, 1999) Han performed a meta-analysis of mammography interventions for minority women demonstrating an average of $7.8 \%$ increase in the rate of mammography.(Han et al., 2009) Access interventions increased the rate of mammography by $15.5 \%$ whereas other individual directed interventions accounted for $9.9 \%$ increase. Combined interventions demonstrated a strong effect on mammography uptake but which component is more 
efficacious than others cannot be ascertained. Han reported that social networks (interventions made by lay health workers and promotoras) would actually lower the use of mammography, raising questions about the effectiveness of culturally sensitive (CS) education delivered by a lay health worker.(Han et al., 2009)

Minorities fear losing confidentiality, thus programs increasing the awareness of the benefits of early detection could ameliorate this problem.( $\mathrm{Wu}$, Colby, Iongi-Filiaga, \& Maskarinec, 2010) This is important because lack of regular screening among African American and Hispanic women is associated with late stage of breast cancer diagnosis.(Henry et al., 2011) Whether health promotion programs to increase mammography uptake should invest in CS education, particularly, using lay health workers remains unclear. The purpose of this metaanalysis is to assess the effectiveness of culturally sensitive programs to increase mammography use by minority women when compared to: 1) usual care, and, 2) delivery through a lay health worker, 3) diverse racial/ethnic groups, such as, differences between Latina versus Asian Pacific descent versus Black women, 4) rural versus urban location.

\section{Methods}

The search strategy searched published materials. First, a limited search of Medline and CINAHL was conducted to identify relevant keywords contained in the title, abstract and subject descriptors. Second, terms identified in this way and the synonyms used by respective databases are used in the extensive search of the literature and, searching from the reference lists and bibliographies of the articles. The abstract is reviewed first, if it met criteria then, the article was reviewed.

\subsection{Study selection}

This systematic review considered studies of minority women at risk of breast cancer that were recent immigrants or that spoke English as a second language or were foreign born. The intervention of interest is an educational program culturally sensitive compared to usual care to increase compliance with mammography. The outcome variable is mammography uptake determined by the patient's self-report or by record review. Study types included are randomized, clinical trials or comparative analysis. Studies conducted with languages other than English are excluded. When there was a discrepancy, two investigators looked at the article and finally, the study was admitted if it met design specifications and all other study inclusion criteria.

\subsection{Search strategy}

Ovid and CINAHL collections were retrieved with the following search terms used in various combinations: "intervention studies" or "patient education" as topic or "cooperative behavior" or "social change" or "interventions" AND "mammography" or "ultrasonography, mammary" or "mass screening" or "early detection of cancer" and "breast neoplasm" AND "Asian Americans" or "African Americans" or "Hispanic Americans" or "Minority groups". Then, limits were placed to humans, female, English, all adult: 19+ years. The first collection had 109 articles. After scanning the abstracts, only 29 were appropriate for further analysis due to outcome was not mammography or the research was geared to follow up mammography instead of screening mammography, or 
the intervention was not considered culturally sensitive, or comparison was between two interventions other than usual care. In CINAHL we only found 2 additional articles and these were not appropriate for this analysis. After reading the selected articles, only 22 articles were appropriate for further analysis. Only 14 studies from 10 publications were appropriate for meta-analysis (Figure 1), 2 additional studies with CS educational intervention among minority women were included for separate analysis due to having a different design (Table $5 a$ and $b$ ).

\subsection{Data abstraction}

The reviewer abstracted data on study design, database, intervention, sample size, age, compliance with mammography, analysis and external validity into standardized data abstraction forms. The quality of the study is assessed using a quality form based on the methods developed by the University of Oxford titled Centre for Evidence Based Medicine critical appraisal tool specifically RCT Appraisal sheet. A grading system for the quality of the data was developed for a total score of 10 points. Studies that scored between 4-10 points were selected allowing flexibility to include studies in the low range. Inclusion criteria included studies with the following variables: 1) women of minority origin grouping all ethnic background into one larger group, 2) age greater than 40 years following the indications for mammography set by the American Cancer Society recommending yearly screening for women $>40$ years, 3) education programs specifically designed to have an intervention described as cultural sensitive or using the same language spoken by the minority group in question, 4) mammography outcome expressed as $\%$ mammography excluding any study not reporting $\%, 5)$ studies designed as pre and post intervention, prospective randomized intervention, controlled randomized trials, clustered randomized trials, and studies of repeated measures, 6) location included minority women from countries other than United States because all countries have minority groups presenting socioeconomic disadvantages that can contribute to health disparities. Subgroups of racial/ethnic women were Latinas, African American and Asian /Middle East. Local health workers (LHW) were considered as intervention type when the article stated it, if the intervention required phone use, training a woman to deliver the information and or when the LHW was expected to intervene verbally in addition to complementing the education with printed materials. Printed materials were considered when sending or giving out tailored letters, culturally based printed material, and behavior based printed material. Whether the rates differ by geographic location, rural versus urban location was abstracted from the text. If the analysis was performed in a major city, it was assumed that urban was the correct location and not rural unless the authors specifically assigned a rural population in the sample. Studies that scored between 4-10 points were selected. Inclusion criteria included studies of: 1) women of minority origin, 2) age greater than 40 years, 3) education programs specifically designed to have an intervention described as cultural sensitive or using the same language as the minority group, 4) mammography outcome expressed as \% mammography, 5) studies designed as pre and post intervention, prospective randomized intervention, controlled randomized trials, clustered randomized trials, and studies of repeated measures, 6) location included minority women in other countries.

Exclusion criteria included studies where the intervention was: 1) not CS education, 2) if the outcome was not expressed as percent mammography or could not be converted to a 
mammography rate, 3) the women were not of minority origin, 4) if data did not include the years 1990 to the present, 4) study design was review, case report, case control but not an intervention, 5) quality rated $<4$.

\subsection{Statistical analysis}

The effectiveness of an educational intervention culturally sensitive to increase mammography use is estimated using meta-analysis with Comprehensive Meta-analysis software, version 2 and will be considered significant with $P$ value $<0.05$. Random effects models were selected a priori to estimate combined study effects. Moreover, statistical heterogeneity of the studies was indicated based on $\mathrm{Q}=14.983, \mathrm{df}=13, \mathrm{p}=.002$ in the initial analysis (Table 2). In the random effects model, variance is partitioned into within study and between studies variance. The weight assigned to each study was estimated by $1 /$ (variance+tau-squared), $C>0$, then tau squared $=(\mathrm{Q}-\mathrm{df}) / \mathrm{C}$ and tau-squared is the between studies variance. The triangular shape of the funnel plot of the standard error by $\log$ odds ratio suggested acceptable publication bias (Figure 1).

\subsection{Intervention and how it might work}

There is no standard definition of cultural sensitivity but it is important because culture influences how minorities view, understand and how they explain cancer. Minority patients value feeling respected. Respect results from dialogue, attention, curiosity, healing, empowerment and self-respect. Cultural sensitivity consists of being responsive to the attitudes, beliefs, feelings and position of minority groups who share common racial, national, religious or cultural traditions.(Hoffman-Goetz \& Friedman, 2006; American Association of Diabetes Educators, 2007) Cultural sensitivity encompasses superficial and deep dimensions. The superficial dimension considers observable behaviors, such as, people, places, language, music, clothing, product brands and food. The deep structure covers intangible factors, for instance, understanding the culture, historical events, social and environmental factors that influence health behaviors. Cultural competence, multicultural, cultural tailoring, racial identity and ethnic identity are all aspects of cultural sensitivity accepted in this review as determinants of the effectiveness of promoting mammography education among minority women. (U.S.Department of Health and Human ServicesOffice of Minority Health, 2001)

\section{Results}

\subsection{Description of the population}

The population consisted of women of minority origin in the United States and abroad. Included were African American, Latina, Asian Pacific and Middle Eastern origin. (Figure 2) The age for mammography testing was older than 40 years for most studies (Table 1). From the two additional studies of different design described separately, Dignan presents the response from Native American Indian women (Table 5a) and Grindel presents a longitudinal study of African American women (Table 5b). An additional study with cluster randomized trial described Asian women response to CS education (Table 5c). Six studies were conducted in rural areas (Table 6). 


\begin{tabular}{|l|}
\hline *Intervention \\
*Comparing 2 \\
interventions(Avis, \\
Smith, Link, \& Goldman, \\
2004),(Calderon et al., \\
2010),(Nguyen et al., \\
2009),(Russell et al., \\
2010),(Sauaia et al., \\
2007),(Skinner et al., \\
1994),(Welsh et al., \\
2005),(Kreuter et al., \\
2010),(Davis et al., \\
1998),(Champion et al., \\
2006) \\
*Not cultural sensitive \\
education(Achat, Close, \\
\& Taylor, 2005),(Crane et \\
al., 1998),(Cronan et al., \\
2008),(Dailey, Kasl, \\
Holford, \& Jones, \\
2007),(Dailey et al., \\
2008),(Danigelis, \\
Worden, Flynn, Skelly, \& \\
Vacek, 2005),(Diamant, \\
Brook, Fink, \& Gelberg, \\
2002),(Fox \& Roetzheim, \\
1994),(Gorin et al., \\
2006),(Menon et al., \\
2007),(Trock et al., \\
1993),(Tu et al., \\
2005),(Michielutte R et \\
al., 2005),(Jibaja-Weiss, \\
Volk, Kingery, Smith, \& \\
Holcomb, 2003) \\
\end{tabular}

\begin{tabular}{l}
\hline *Outcome \\
*Different outcome or \\
measure of outcome(Agho, \\
Mosley, Rivers, \& Parker, \\
2007),(Consedine et al., \\
2007),(Consedine, Magai,
\end{tabular}

Horton, Neugut, \& Gillespie, 2005),(del Carmen et al., 2003),(Hall et al., 2007),(Holt \& Klem, 2005),(Holt, Lee, \& Wright, 2008),(Kelley, 2004),(Valdez, Banerjee, Ackerson, \& Fernandez, 2002),(Young, Waller, Jr., \& Smitherman, 2002)

\section{*Diagnostic}

mammography(Bastani, Mojica, Berman, \& Ganz, 2010),(Ell, Vourlekis, Lee, \& Xie, 2007),(Jones et al., 2005),(Maxwell, Jo, Crespi, Sudan, \& Bastani, 2010)

*Quality Low(Kernohan, 1996),(Zhu et al., 2002)

Included(Beach et al., 2007),(Bird et al., 1998),(Cohen \& Azaiza, 2010), (Fernandez et al., 2009),(Grindel, Brown, Caplan, \& Blumenthal, 2004),(Jenkins et al., 1999),(Kreuter et al., 2005),(Navarro et al., 1995),(Nguyen et al., 2001), (West et al., 2004)
*No RCT or intervention studies(Abraido-Lanza, Chao, \& Gammon, 2004),(Adams et al., 2007), (Ahmad, Cameron JL, \& Stewart DE, 2005),(Ahmed et al., 2005),(Anagnostopoulos \& Spanea, 2005), (Borrayo \& Guarnaccia, 2000),(Borrayo et al., 2009),(Calvocoressi et al., 2004),(Calvocoressi et al., 2008),(Carter, Park, Moadel, Cleary, \& Morgan, 2002),(Coughlin, Uhler, Richards, \& Wilson, 2003),(Dow Meneses K \& Yarbro CH, 2007),(Erwin et al., 2007),(Eun, Lee, Kim, \& Fogg, 2009),(Finney, Tumiel-Berhalter, Fox, \& Jaen, 2006),(Frazier, Jiles, \& Mayberry, 1996; Edwards et al., 2006),(Friedman et al., 1995),(Fulton, 1992),(Fulton, Rakowski, \& Jones, 1995),(Gail et al., 2007),(Gandhi et al., 2010),(Garbers, Jessop, Foti, Uribelarrea, \& Chiasson, 2003),(Glanz, Resch, Lerman, \& Rimer, 1996),(Harris, Miller, \& Davis, 2003),(Jafri, Ayyala, Ozonoff, JordanGray, \& Slanetz, 2008),(Juon, Kim, Shankar, \& Han, 2004),(Kandula, Wen, Jacobs, \& Lauderdale, 2006),(Kaplan et al., 1996),(Kerlikowske, Creasman, Leung, Smith-Bindman, \& Ernster, 2005),(Kiger, 2003),(Kline, 2007),(Kreuter, Lukwago, Bucholtz, Clark, \& Sanders-Thompson, 2003),(Lackland, Dunbar, Keil, Knapp, \& O'Brien, 1991),(Legler et al., 2002),(Luquis \& Villanueva Cruz, 2006), (Madan et al., 2002),(Mandelblatt et al., 2005),(Maxwell, Bastani, \& Warda, 2000),(McAlister et al., 1995),(Meade, Calvo, \& Cuthbertson, 2002),(O'Malley, Forrest, \& Mandelblatt, 2002),(Oetzel, De, Ginossar, \& Sanchez, 2007),(Orians et al., 2004),(Paskett et al., 2004),(Powe \& Cooper, 2008),(PurcStephenson \& Gorey, 2008),(Qureshi, Thacker, Litaker, \& Kippes, 2000),(Ramirez et al., 2000),(Rawl, Champion, Menon, \& Foster, 2000),(Roetzheim et al., 1992),(Sadler et al., 2009),(Saint-Germain \& Longman, 1993),(Sassi, Luft, \& Guadagnoli, 2006),(Selvin \& Brett, 2003),(Shin et al., 2010),(Skaer, Robison, Sclar, \& Harding, 1996; Strzelczyk \& Dignan, 2002),(Suarez \& Pulley, 1995),(Suh, 2008),(Tejeda, Thompson, Coronado, Heagerty, \& Martin, 2009),(Watts, Merrell, Murphy, \& Williams, 2004),(Wee, McCarthy, Davis, \& Phillips, 2004),(Welsh et al., 2005),(Wells \& Roetzheim, 2007),(Williams, Mabiso, Lo, \& Penner, 2010),(Yang et al., 2009),(Yankaskas \& Gill, 2005),(Underwood SM \& M Canales, 2005),(Dignan et al., 2005),(Jandorf et al., 2008),(Mishra et al., 2007)

Fig. 1. Medline articles \& added references included and excluded* by study design, total 108. 


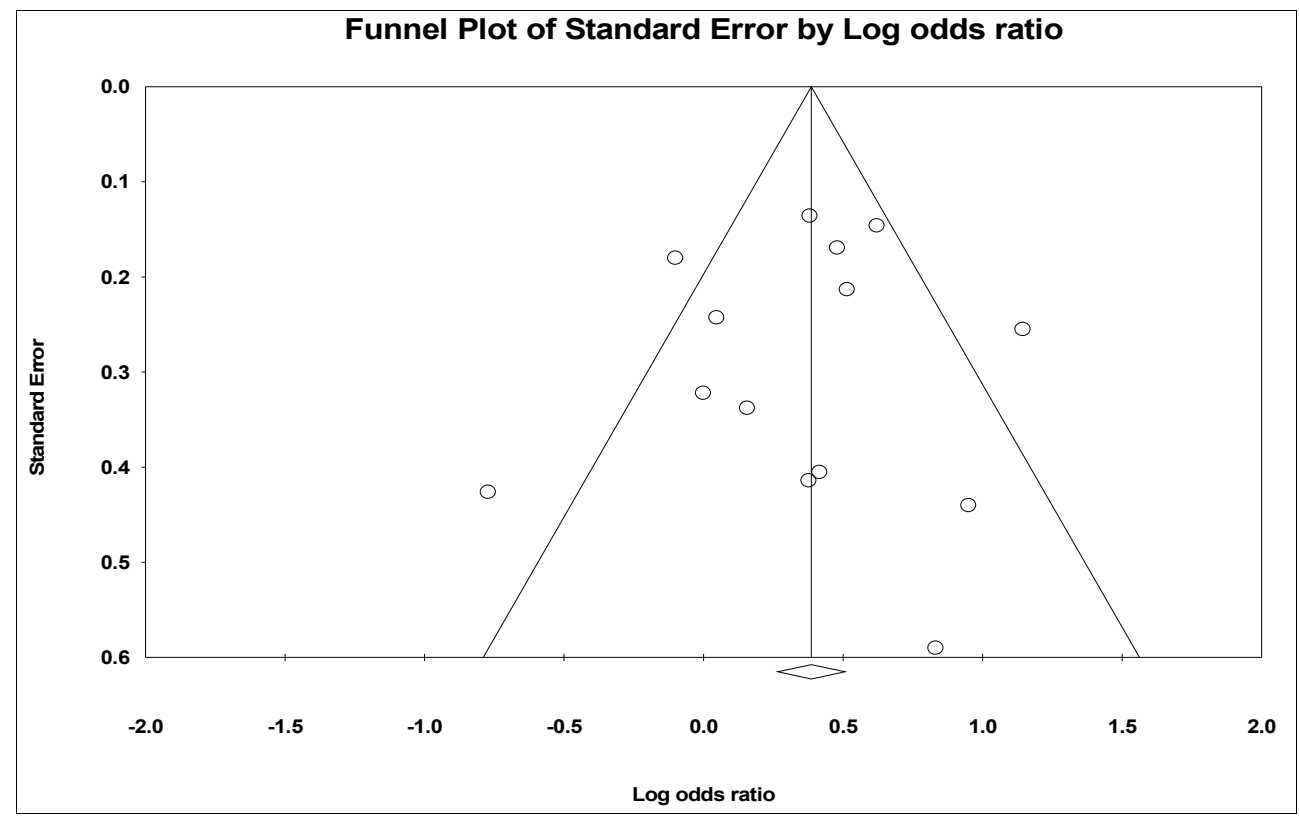

Fig. 2. Triangular shape of the funnel plot of the meta-analysis using CS education program to increase mammography uptake.

\subsection{Usual care versus culturally sensitive education}

The odds ratio (OR) of obtaining mammography were almost 1.5 times more likely for minority women who participated in CS education program than from usual care $(\mathrm{OR}=1.440$ (95\% CI=1.164-1.780), p<0.001)) (Table 2).

\subsubsection{Lay health workers}

One question was if delivery of CS education through lay health workers compared to usual care increased mammography uptake? The odds that minority women would engaged in screening mammography after receiving CS education through a lay health worker increases 1.7 times than with usual care alone (OR=1.655 (95\% CI=1.207 -2.267)) (Table 3).

\subsubsection{Racial/ethnic groups}

Our next question tested whether the effect size of CS education was homogeneous through all racial/ethnic groups (Table 4). When analyzing the odds of screening mammography after CS education by racial ethnic group, the odds of receiving screening was 1.569 higher than with usual care $(\mathrm{OR}=1.569$ (95\% $\mathrm{CI}=1.310-1.838)$ ). All minority women responded positively to CS education. Latinas were more likely to obtain screening mammography after a CS education program than without it $(\mathrm{OR}=1.74$ (95\% CI=1.43-2.10)). African American women have 1.2 higher odds of obtaining screening mammography after CS education program than with only usual care (OR 1.156 (95\% CI=0.834 -1.601), but there was great variability within studies. Asian and Middle Eastern women have 1.6 higher odds of 
obtaining screening with CS education than with usual care R/E, race/ethnicity; AA, African-American; RCT, randomized controlled trial; prosp interv, prospective interventional; LHW, lay health worker; $(\mathrm{OR}=1.64,95 \% \mathrm{CI}=0.98-2.80)$. Looking closely at Nguyen's study, he used a combination including media campaign, and the women with higher number of exposures were more likely to obtain mammography. We have no way of adjusting for number of exposures with these data, therefore, Nguyen's study was removed and the effect size is in favor of CS education modestly increasing in favor of obtaining screening mammography when compared to usual care (OR=1.83, 95\% CI (1.44-2.33). In summary, the racial ethnic groups in this meta-analysis have similar effects $(p=0.28)$, the higher Latinas odds ratio is not statistically different from other racial/ethnic groups.

\begin{tabular}{|c|c|c|c|c|c|c|c|c|c|c|}
\hline $\begin{array}{l}\text { Study } \\
\text { name }\end{array}$ & Design & Age & $\mathrm{R} / \mathrm{E}$ & Rural & $\begin{array}{c}\text { Type of } \\
\text { intervention }\end{array}$ & Rank as & I & $\mathbf{N}$ & $\mathrm{C}$ & $\mathbf{N}$ \\
\hline Beach 2007 & RCT & $50-69$ & Latina & $\mathrm{NO}$ & Phone & Phone & 0.72 & 431 & 0.58 & 417 \\
\hline \multirow[t]{3}{*}{$\begin{array}{c}\text { Kreuter } \\
2005\end{array}$} & $\begin{array}{l}\text { prosp } \\
\text { interv }\end{array}$ & $40-65$ & AA & $\mathrm{NO}$ & $\begin{array}{c}\text { behavioral } \\
\text { print tailored }\end{array}$ & Printed & 0.645 & 48 & 0.545 & 55 \\
\hline & $\begin{array}{l}\text { prosp } \\
\text { interv }\end{array}$ & $40-65$ & AA & NO & Combined & printed & 0.756 & 45 & 0.545 & 55 \\
\hline & $\begin{array}{l}\text { prosp } \\
\text { interv }\end{array}$ & $40-65$ & AA & NO & cult print & printed & 0.636 & 44 & 0.545 & 55 \\
\hline \multirow[t]{3}{*}{ West 2004} & $\mathrm{RCT}$ & $50-80$ & $\mathrm{AA}$ & YES & Print & printed & 0.14 & 159 & 0.14 & 161 \\
\hline & $\mathrm{RCT}$ & $50-80$ & $\mathrm{AA}$ & YES & tailored print & printed & 0.07 & 118 & 0.14 & 161 \\
\hline & $\mathrm{RCT}$ & $50-80$ & AA & YES & LHW & LHW & 0.16 & 119 & 0.14 & 161 \\
\hline $\begin{array}{c}\text { Fernandez } \\
2010\end{array}$ & $\begin{array}{l}\text { prosp } \\
\text { interv }\end{array}$ & $>50$ & Latina & YES & LHW+print & LHW & 0.408 & 310 & 0.299 & 310 \\
\hline Erwin 1999 & $\begin{array}{l}\text { prosp } \\
\text { interv }\end{array}$ & $40-93$ & AA & YES & LHW & LHW & 0.644 & 152 & 0.633 & 142 \\
\hline Cohen 2010 & CRT & $40-65$ & Arab & MIXED & LHW & LHW & 0.385 & 42 & 0.214 & 24 \\
\hline $\begin{array}{c}\text { Navarro } \\
1998\end{array}$ & CRT & $>40$ & Latina & $\begin{array}{c}\text { Un- } \\
\text { known }\end{array}$ & LHW & LHW & 0.564 & 199 & 0.436 & 162 \\
\hline $\begin{array}{c}\text { Nguyen } \\
2000\end{array}$ & $\begin{array}{l}\text { prosp } \\
\text { interv }\end{array}$ & $>40$ & $\begin{array}{l}\text { Vietna } \\
\text { mese }\end{array}$ & NO & Combined & combined & 0.689 & 289 & 0.71 & 297 \\
\hline Bird 1998 & $\begin{array}{l}\text { prosp } \\
\text { interv }\end{array}$ & $>40$ & $\begin{array}{l}\text { Vietna } \\
\text { mese }\end{array}$ & NO & LHW & LHW & 0.55 & 140 & 0.28 & 137 \\
\hline $\begin{array}{c}\text { Jenkins } \\
1999\end{array}$ & $\begin{array}{l}\text { prosp } \\
\text { interv }\end{array}$ & $>40$ & $\begin{array}{l}\text { Vietna } \\
\text { mese }\end{array}$ & NO & $\begin{array}{c}\text { combined/ } \\
\text { media }\end{array}$ & combined & 0.551 & 454 & 0.456 & 422 \\
\hline
\end{tabular}

Table 1. Description of studies included in meta-analysis, 10 publications, 14 studies.

Dignan (2005) reported that among the American Indian population a telephone call using a lay health worker (Dignan et al., 2005) demonstrated higher odds than face-to-face CS education to obtain screening mammography (Table 5a).(Dignan et al., 2005) Using either one of those interventions would have 1.66 higher odds of obtaining mammography than not intervening (OR=1.66 (95\% CI: 1.293-2.134). Of interest, Grindel's study was assessed separately because is a longitudinal design using same woman at baseline as the preintervention (Table 5b). The study demonstrated a strong effect size where African American women had 2.2 higher odds ratio of obtaining screening mammography given a program of CS education compared to their baseline (pre-intervention). A cluster randomized trial corroborates a similar effect size to the meta-analysis of the 10 studies (Table 5c). The odds ratio of obtaining screening mammography after the intervention was 1.5 times that of usual care. Again, we can observe more variability in the African American women group but this could be related to power due to the small sample size used compared to the Jenkins study of Vietnamese women. This study had among the lowest standard error and would have created statistical problems if treated as un-clustered studies because the within study error would be underestimated. 


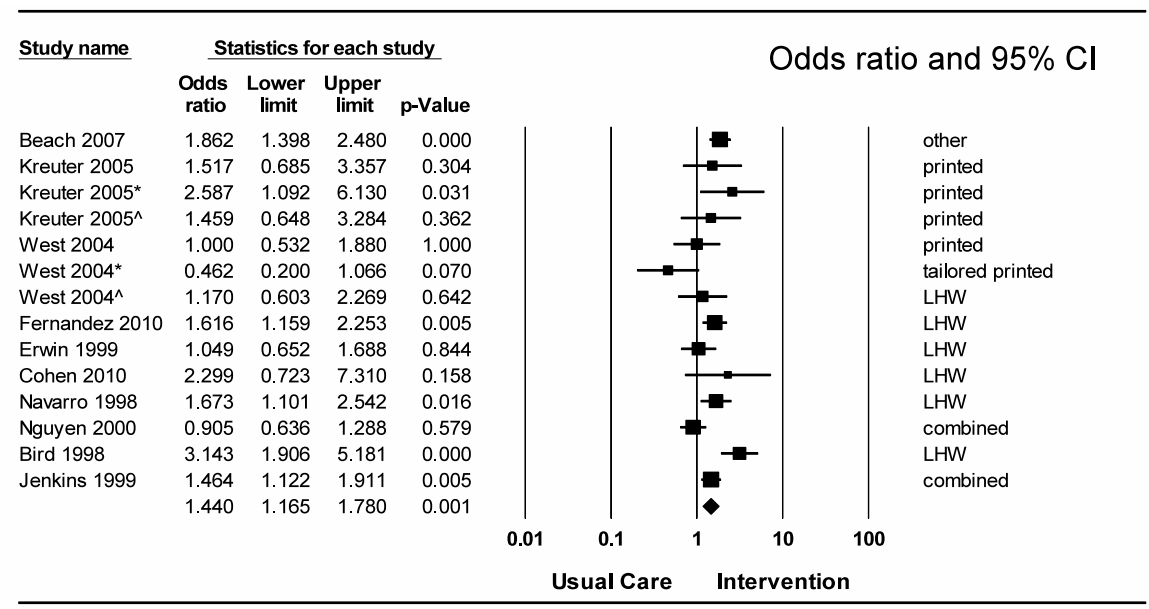

\section{Overall}

Table 2. Usual care versus culturally sensitive education, 10 studies, 14 subgroups, using random effects model.

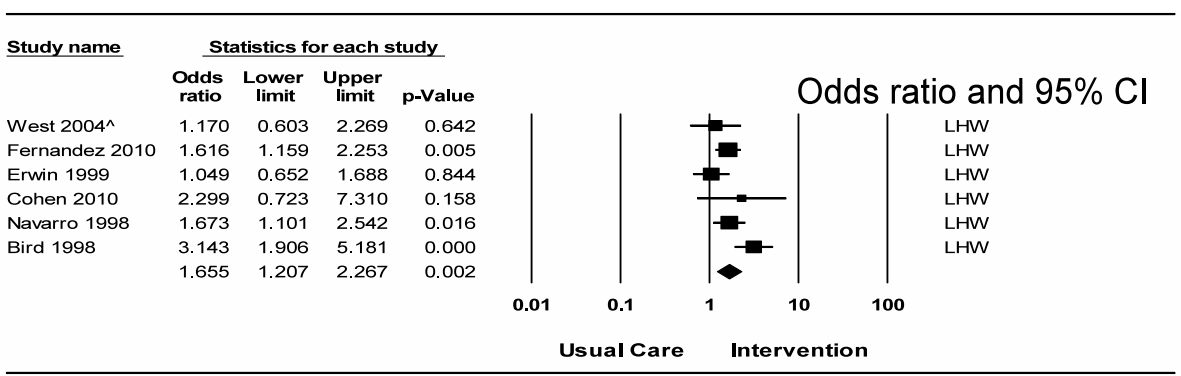

\section{Overall}

Table 3. Effect size of culturally sensitive education versus usual care with lay health worker, 6 studies. 


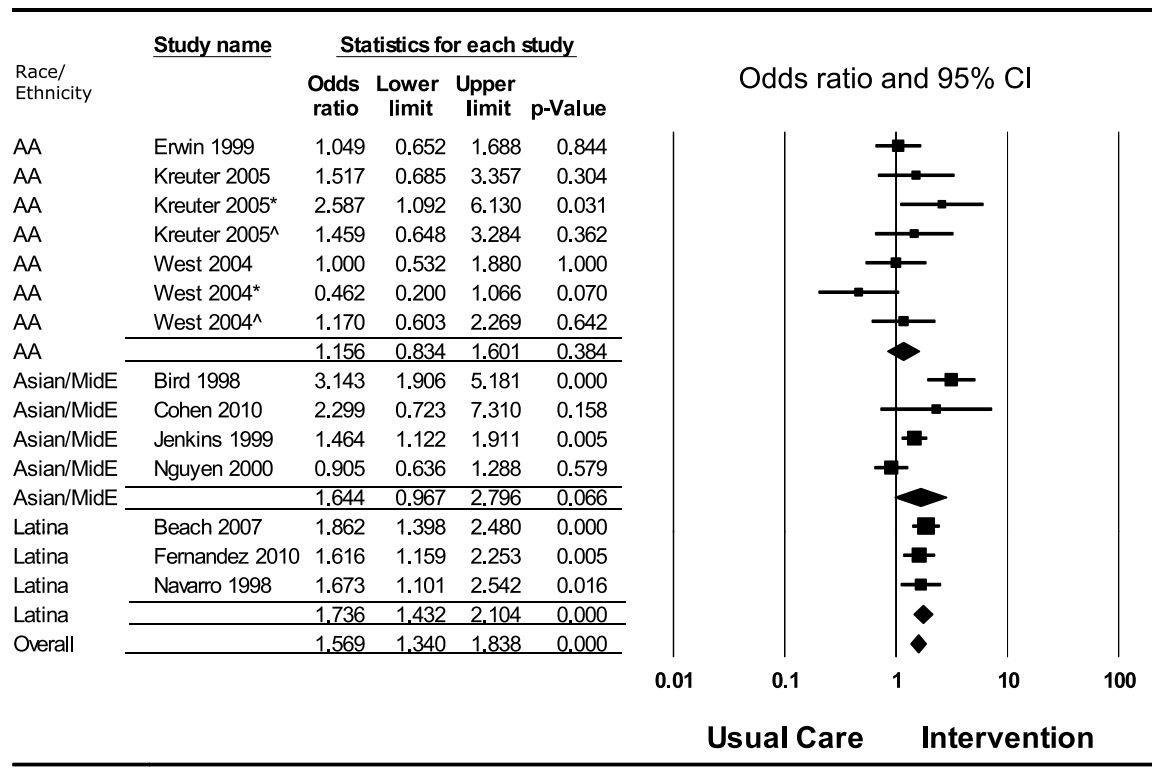

Table 4. Effectiveness of culturally sensitive education to increase mammography uptake by race/ethnicity.

\section{A. Baseline comparison - Native American}

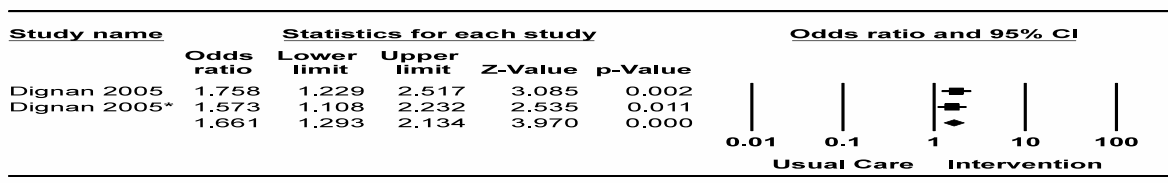

\section{Overall}

(a) Native American women 


\section{B. Longitudinal - AA}

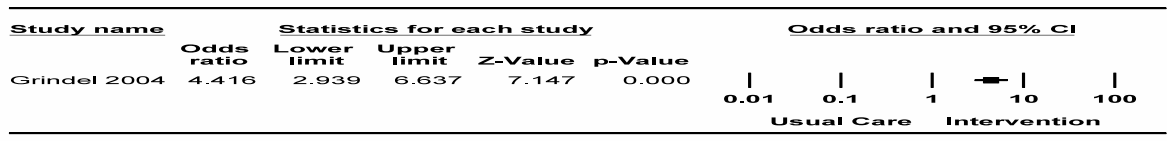

(b) African American Women

\section{Cluster randomized}

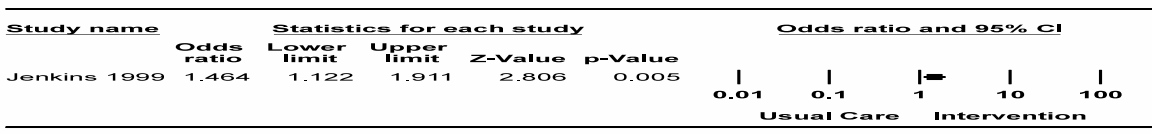

c) Effect size of mammography uptake after intervention in minority women, cluster randomized trials.

Table 5. Additional studies with different design presenting minority population of women subjected to CS education and their mammography uptake: a) American Indian b) African American.

\subsubsection{Rural versus urban location}

The odds ratio that minority women living in a rural area would obtain screening mammography after CS education were not statistically improved compared to usual care $(\mathrm{OR}=1.08$ (95\% CI= 0.75-1.56)) (Table 6). The odds that minority women living in urban areas would obtain screening mammography after CS education were 1.7 higher than for those without the intervention ( $\mathrm{OR}=1.66$ (95\% CI=1.21-2.27)). Also, it depends on the type of intervention, thus lay health workers or promotoras present greater odds of obtaining screening mammography among rural minority women $(\mathrm{OR}=1.3(95 \% \mathrm{CI}=1.06-1.75))$ than usual care. However, the effect of lay health workers was limited to one article among those living in urban areas $(\mathrm{OR}=3.14(95 \% \mathrm{CI}=1.9-5.2))$. 


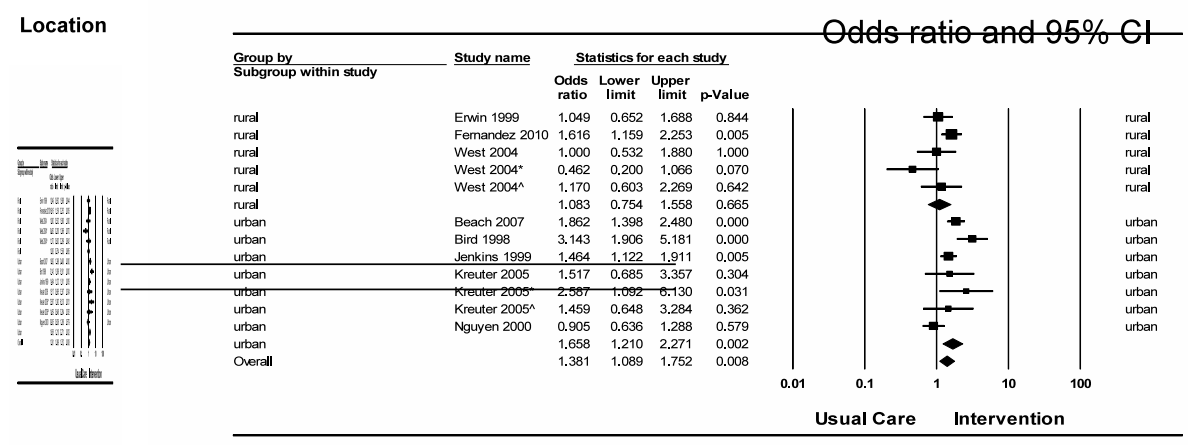

Overall

Table 6. Effect size of culturally sensitive education on mammography uptake by location: urban versus rural.

\section{Discussion}

Culturally sensitive education programs are effective interventions to increase mammography uptake among minority women. Delivery of culturally sensitive intervention by lay health workers increase modestly mammography uptake among minority women. However, delivery of CS education by lay health workers was more effective than usual care.

Effective interventions to increase mammography uptake include mailed educational materials, letters of invitation with phone calls, training and direct reminders to women, and home visits(Legler et al., 2002),(Nguyen et al., 2006) just as for cervical screenings. Asian women preferred women physicians performing the evaluation perhaps because of modesty, sexual behavior and the fear of losing confidentiality, in other words, having others know of the potential breast cancer diagnosis.(Nguyen, McPhee, Nguyen, Lam, \& Mock, 2002), (Remennick, 2006) Nowadays minorities who do not have documented citizenship fear deportation avoiding preventive cancer care.

Our meta-analysis confirms that delivery of CS education through a lay health worker compared to usual care alone increases the likelihood of obtaining screening. CS interventions other than educational could have a greater impact depending on the barrier impeding mammography uptake. Lay health workers that share cultural and linguistic characteristics communicating the breast cancer prevention message may reduce an important proportion of the disparity but not the entire multifaceted disparity. For instance, access enhancing, individual and system directed and combinations of effective 
interventions may remove important barriers that cannot be addressed by an educational intervention. In other words, educational interventions increase the awareness and knowledge of screening behaviors but cannot remove barriers related to lack of health insurance, lack of regular provider or a physician recommending the test.(Peek \& Han, 2004) Furthermore, Legler recommended measuring the individual components of an effective combination of interventions.(Legler et al., 2002) This is somewhat complicated because multiple interventions may have interaction potentiating the effect of one of the variables or the effect may vary according to the environmental elements present.

The effect of removing linguistic barriers is unequal to almost any other CS intervention among Latinas and lay health workers. Phone counseling can invariably improve effectiveness in communication. Much harder is to effectively intervene to mitigate mistrust in the health care system that is rampant among minority women.(Peek \& Han, 2004),(Samsudeen, Douglas, \& Bhopal, 2011) Alleviating healthcare mistrust through social networks and delivery through lay health workers could have a greater impact in changing health behavior towards cancer prevention compared to usual care or other interventions akin to tailored letters or printed materials.

For women living in rural areas, we can see less benefit from CS education than for women in urban areas. In part, studies from rural areas had flaws based on limitations from lack of facilities in the area of the intervention, low response rates due to many being migrant farmers lost to follow up and approaching minority women who rarely or never access health services. However, the odds ratios range widely and some studies such as Fernandez and Erwin reported positive effectiveness of CS education among minority women in rural areas. In particular, delivering CS education through lay health workers suggests that rural minority women face problems beyond lack of awareness. Some of these barriers comprise access issues, for instance, lack of health insurance, regular provider and the manpower providing the services in rural areas.

Some limitations of this meta-analysis include the variance caused by having all races and ethnicities combined together as minority women. However, considering that many minority women share a disadvantage background makes ground to compile their data together. Another limitation is the low quality of most randomized controlled trials (RCT) impacting the sample size thus the power that may underestimate differences between the intervention and usual care groups. Additionally, most data from RCT is self-reported by the women, a source of recall bias. Another limitation is that LHW complement their work by providing booklets and other printed materials limiting the assessment of the effect of LHW only or printed material only. In this study, the intervention LHW considered providing printed materials to educate minority women.

\section{Conclusion}

CS education is more effective than usual care to increase screening mammography behaviors among minority women. These data support that minority women are likely to increase mammography uptake after this intervention regardless of the racial/ethnic group. Delivering CS education through a lay health worker is more effective than usual care alone. 
TO POLICY MAKERS: Minority women benefit from culturally sensitive education to increase screening mammography uptake. Investing in culturally sensitive education through a lay health worker is an effective intervention to reduce the disproportion of screening mammography uptake among minority women.

\section{Acknowledgment}

This publication was supported by grant [Caban] K08 CA111622 from the National Cancer Institute.

\section{References}

Abraido-Lanza, A. F., Chao, M. T., \& Gammon, M. D. (2004). Breast and cervical cancer screening among Latinas and non-Latina whites. Am.J.Public Health, 94, 1393-1398.

Achat, H., Close, G., \& Taylor, R. (2005). Who has regular mammograms? Effects of knowledge, beliefs, socioeconomic status, and health-related factors. Prev.Med., 41, 312-320.

Adams, E. K., Breen, N., \& Joski, P. J. (2007). Impact of the National Breast and Cervical Cancer Early Detection Program on mammography and Pap test utilization among white, Hispanic, and African American women: 1996-2000. Cancer, 109, 348-358.

Agho, A. O., Mosley, B. W., Rivers, P. A., \& Parker, S. (2007). Utilization of mammography services among elderly rural and urban African American women. Health Education Journal, 66, 245-261.

Ahmad, F., Cameron JL, \& Stewart DE. (2005). A tailored intervention to promote breast cancer screening among South Asian immigrant women. Social Science \& Medicine 60[3], 575-586.

Ahmed, N. U., Fort, J. G., Elzey, J. D., \& Belay, Y. (2005). Empowering factors for regular mammography screening in under-served populations: pilot survey results in Tennessee. Ethn.Dis., 15, 387-394.

American Association of Diabetes Educators (2007). AADE position statement. Cultural sensitivity and diabetes education: recommendations for diabetes educators. Diabetes Educ., 33, 41-44.

Anagnostopoulos, F. \& Spanea, E. (2005). Assessing illness representations of breast cancer: a comparison of patients with healthy and benign controls. J.Psychosom.Res., 58, 327-334.

Avis, N. E., Smith, K. W., Link, C. L., \& Goldman, M. B. (2004). Increasing mammography screening among women over age 50 with a videotape intervention. Prev.Med., 39, 498-506.

Bastani, R., Mojica, C. M., Berman, B. A., \& Ganz, P. A. (2010). Low-income women with abnormal breast findings: results of a randomized trial to increase rates of diagnostic resolution. Cancer Epidemiol.Biomarkers Prev., 19, 1927-1936.

Beach, M. L., Flood, A. B., Robinson, C. M., Cassells, A. N., Tobin, J. N., Greene, M. A. et al. (2007). Can language-concordant prevention care managers improve cancer screening rates? Cancer Epidemiol.Biomarkers Prev., 16, 2058-2064.

Bird, J. A., McPhee, S. J., Ha, N. T., Le, B., Davis, T., \& Jenkins, C. N. (1998). Opening pathways to cancer screening for Vietnamese-American women: lay health workers hold a key. Prev.Med., 27, 821-829. 
Borrayo, E. A. \& Guarnaccia, C. A. (2000). Differences in Mexican-born and U.S.-born women of Mexican descent regarding factors related to breast cancer screening behaviors. Health Care Women Int., 21, 599-613.

Borrayo, E. A., Hines, L., Byers, T., Risendal, B., Slattery, M. L., Sweeney, C. et al. (2009). Characteristics associated with mammography screening among both Hispanic and non-Hispanic white women. J.Womens Health (Larchmt.), 18, 1585-1894.

Calderon, J. L., Bazargan, M., Sangasubana, N., Hays, R. D., Hardigan, P., \& Baker, R. S. (2010). A comparison of two educational methods on immigrant Latinas breast cancer knowledge and screening behaviors. J.Health Care Poor Underserved, 21, 7690.

Calvocoressi, L., Kasl, S. V., Lee, C. H., Stolar, M., Claus, E. B., \& Jones, B. A. (2004). A prospective study of perceived susceptibility to breast cancer and nonadherence to mammography screening guidelines in African American and White women ages 40 to 79 years. Cancer Epidemiol.Biomarkers Prev., 13, 2096-2105.

Calvocoressi, L., Sun, A., Kasl, S. V., Claus, E. B., \& Jones, B. A. (2008). Mammography screening of women in their 40s: impact of changes in screening guidelines. Cancer, 112, 473-480.

Carter, J., Park, E. R., Moadel, A., Cleary, S. D., \& Morgan, C. (2002). Cancer knowledge, attitudes, beliefs, and practices (Carter et al., 2002) of disadvantaged women in the South Bronx. J.Cancer Educ., 17, 142-149.

Champion, V. L., Springston, J. K., Zollinger, T. W., Saywell, R. M., Jr., Monahan, P. O., Zhao, Q. et al. (2006). Comparison of three interventions to increase mammography screening in low income African American women. Cancer Detect.Prev., 30, 535-544.

Cohen, M. \& Azaiza, F. (2010). Increasing breast examinations among arab women using a tailored culture-based intervention. Behav.Med., 36, 92-99.

Consedine, N. S., Horton, D., Magai, C., \& Kukafka, R. (2007). Breast screening in response to gain, loss, and empowerment framed messages among diverse, low-income women. J.Health Care Poor Underserved, 18, 550-566.

Consedine, N. S., Magai, C., Horton, D., Neugut, A. I., \& Gillespie, M. (2005). Health belief model factors in mammography screening: testing for interactions among subpopulations of Caribbean women. Ethn.Dis., 15, 444-452.

Coughlin, S. S., Uhler, R. J., Richards, T., \& Wilson, K. M. (2003). Breast and cervical cancer screening practices among Hispanic and non-Hispanic women residing near the United States-Mexico border, 1999-2000. Fam.Community Health, 26, 130-139.

Crane, L. A., Leakey, T. A., Rimer, B. K., Wolfe, P., Woodworth, M. A., \& Warnecke, R. B. (1998). Effectiveness of a telephone outcall intervention to promote screening mammography among low-income women. Prev.Med., 27, S39-S49.

Cronan, T. A., Villalta, I., Gottfried, E., Vaden, Y., Ribas, M., \& Conway, T. L. (2008). Predictors of mammography screening among ethnically diverse low-income women. J.Womens Health (Larchmt.), 17, 527-537.

Curtis, E., Quale, C., Haggstrom, D., \& Smith-Bindman, R. (2008). Racial and ethnic differences in breast cancer survival: how much is explained by screening, tumor severity, biology, treatment, comorbidities, and demographics? Cancer, 112, 171180.

Dailey, A. B., Kasl, S. V., Holford, T. R., \& Jones, B. A. (2007). Perceived racial discrimination and nonadherence to screening mammography guidelines: results from the race 
differences in the screening mammography process study. Am.J.Epidemiol., 165, 1287-1295.

Dailey, A. B., Kasl, S. V., \& Jones, B. A. (2008). Does gender discrimination impact regular mammography screening? Findings from the race differences in screening mammography study. J.Womens Health (Larchmt.), 17, 195-206.

Danigelis, N. L., Worden, J. K., Flynn, B. S., Skelly, J. M., \& Vacek, P. M. (2005). Increasing mammography screening among low-income African American women with limited access to health information. Prev.Med., 40, 880-887.

Davis, T. C., Berkel, H. J., Arnold, C. L., Nandy, I., Jackson, R. H., \& Murphy, P. W. (1998). Intervention to increase mammography utilization in a public hospital. J.Gen.Intern.Med., 13, 230-233.

Dein, S. (2004). Explanatory models of and attitudes towards cancer in different cultures. Lancet Oncol., 5, 119-124.

del Carmen, M. G., Hughes, K. S., Halpern, E., Rafferty, E., Kopans, D., Parisky, Y. R. et al. (2003). Racial differences in mammographic breast density. Cancer, 98, 590-596.

Diamant, A. L., Brook, R. H., Fink, A., \& Gelberg, L. (2002). Use of preventive services in a population of very low-income women. J.Health Care Poor Underserved, 13, 151-163.

Dignan, M. B., Burhansstipanov, L., Hariton, J., Harjo, L., Rattler, T., Lee, R. et al. (2005). A comparison of two Native American Navigator formats: face-to-face and telephone. Cancer Control, 12 Suppl 2, 28-33.

Dow Meneses K \& Yarbro CH. (2007). Cultural perspectives of international breast health and breast cancer education. Journal of Nursing Scholarship 39[2], 105-112.

Edwards, A. G., Evans, R., Dundon, J., Haigh, S., Hood, K., \& Elwyn, G. J. (2006). Personalised risk communication for informed decision making about taking screening tests. Cochrane.Database.Syst.Rev., CD001865.

Ell, K., Vourlekis, B., Lee, P. J., \& Xie, B. (2007). Patient navigation and case management following an abnormal mammogram: a randomized clinical trial. Prev.Med., 44, 2633.

Erwin, D. O., Johnson, V. A., Trevino, M., Duke, K., Feliciano, L., \& Jandorf, L. (2007). A comparison of African American and Latina social networks as indicators for culturally tailoring a breast and cervical cancer education intervention. Cancer, 109, 368-377.

Eun, Y., Lee, E. E., Kim, M. J., \& Fogg, L. (2009). Breast cancer screening beliefs among older Korean American women. J.Gerontol.Nurs., 35, 40-50.

Fernandez, M. E., Gonzales, A., Tortolero-Luna, G., Williams, J., Saavedra-Embesi, M., Chan, W. et al. (2009). Effectiveness of Cultivando la Salud: a breast and cervical cancer screening promotion program for low-income Hispanic women. Am.J.Public Health, 99, 936-943.

Finney, M. F., Tumiel-Berhalter, L. M., Fox, C., \& Jaen, C. R. (2006). Breast and cervical cancer screening for Puerto Ricans, African Americans, and non-Hispanic whites attending inner-city family practice centers. Ethn.Dis., 16, 994-1000.

Fox, R. (2006). Informed choice in screening programmes: do leaflets help? A critical literature review. J.Public Health (Oxf), 28, 309-317.

Fox, S. A. \& Roetzheim, R. G. (1994). Screening mammography and older Hispanic women. Current status and issues. Cancer, 74, 2028-2033. 
Frazier, E. L., Jiles, R. B., \& Mayberry, R. (1996). Use of screening mammography and clinical breast examinations among black, Hispanic, and white women. Prev.Med., 25, 118125.

Friedman, L. C., Webb, J. A., Weinberg, A. D., Lane, M., Cooper, H. P., \& Woodruff, A. (1995). Breast cancer screening: racial/ethnic differences in behaviors and beliefs. J.Cancer Educ., 10, 213-216.

Fulton, J. P. (1992). Breast cancer screening among low-income Hispanic women in Rhode Island. R.I.Med., 75, 32-33.

Fulton, J. P., Rakowski, W., \& Jones, A. C. (1995). Determinants of breast cancer screening among inner-city Hispanic women in comparison with other inner-city women. Public Health Rep., 110, 476-482.

Gail, M. H., Costantino, J. P., Pee, D., Bondy, M., Newman, L., Selvan, M. et al. (2007). Projecting individualized absolute invasive breast cancer risk in African American women. J.Natl.Cancer Inst., 99, 1782-1792.

Gandhi, S., Rovi, S., Vega, M., Johnson, M. S., Ferrante, J., \& Chen, P. H. (2010). Intimate partner violence and cancer screening among urban minority women. J.Am.Board Fam.Med., 23, 343-353.

Garbers, S., Jessop, D. J., Foti, H., Uribelarrea, M., \& Chiasson, M. A. (2003). Barriers to breast cancer screening for low-income Mexican and Dominican women in New York City. J.Urban.Health, 80, 81-91.

Glanz, K., Resch, N., Lerman, C., \& Rimer, B. K. (1996). Black-white differences in factors influencing mammography use among employed female health maintenance organization members. Ethn.Health, 1, 207-220.

Gorin, S. S., Ashford, A. R., Lantigua, R., Hossain, A., Desai, M., Troxel, A. et al. (2006). Effectiveness of academic detailing on breast cancer screening among primary care physicians in an underserved community. J.Am.Board Fam.Med., 19, 110-121.

Grindel, C. G., Brown, L., Caplan, L., \& Blumenthal, D. (2004). The effect of breast cancer screening messages on knowledge, attitudes, perceived risk, and mammography screening of African American women in the rural South. Oncol.Nurs.Forum, 31, 801-808.

Hall, C. P., Hall, J. D., Pfriemer, J. T., Wimberley, P. D., \& Jones, C. H. (2007). Effects of a culturally sensitive education program on the breast cancer knowledge and beliefs of Hispanic women. Oncol.Nurs.Forum, 34, 1195-1202.

Han, H. R., Lee, J. E., Kim, J., Hedlin, H. K., Song, H., \& Kim, M. T. (2009). A meta-analysis of interventions to promote mammography among ethnic minority women. Nurs.Res., 58, 246-254.

Harris, D. M., Miller, J. E., \& Davis, D. M. (2003). Racial differences in breast cancer screening, knowledge and compliance. J.Natl.Med.Assoc., 95, 693-701.

Henry, K. A., Boscoe, F. P., Johnson, C. J., Goldberg, D. W., Sherman, R., \& Cockburn, M. (2011). Breast Cancer Stage at Diagnosis: Is Travel Time Important? J.Community Health.

Hoffman-Goetz, L. \& Friedman, D. B. (2006). A systematic review of culturally sensitive cancer prevention resources for ethnic minorities. Ethn.Dis., 16, 971-977.

Holt, C. L. \& Klem, P. R. (2005). As you go, spread the word: spiritually based breast cancer education for African American women. Gynecol.Oncol., 99, S141-S142. 
Holt, C. L., Lee, C., \& Wright, K. (2008). A spiritually based approach to breast cancer awareness: cognitive response analysis of communication effectiveness. Health Commun., 23, 13-22.

Jafri, N. F., Ayyala, R. S., Ozonoff, A., Jordan-Gray, J., \& Slanetz, P. J. (2008). Screening mammography: does ethnicity influence patient preferences for higher recall rates given the potential for earlier detection of breast cancer? Radiology, 249, 785-791.

Jandorf, L., Bursac, Z., Pulley, L., Trevino, M., Castillo, A., \& Erwin, D. O. (2008). Breast and cervical cancer screening among Latinas attending culturally specific educational programs. Prog.Community Health Partnersh., 2, 195-204.

Jenkins, C. N., McPhee, S. J., Bird, J. A., Pham, G. Q., Nguyen, B. H., Nguyen, T. et al. (1999). Effect of a media-led education campaign on breast and cervical cancer screening among Vietnamese-American women. Prev.Med., 28, 395-406.

Jibaja-Weiss, M. L., Volk, R. J., Kingery, P., Smith, Q. W., \& Holcomb, J. D. (2003). Tailored messages for breast and cervical cancer screening of low-income and minority women using medical records data. Patient.Educ.Couns., 50, 123-132.

Jones, B. A., Dailey, A., Calvocoressi, L., Reams, K., Kasl, S. V., Lee, C. et al. (2005). Inadequate follow-up of abnormal screening mammograms: findings from the race differences in screening mammography process study (United States). Cancer Causes Control, 16, 809-821.

Juon, H. S., Kim, M., Shankar, S., \& Han, W. (2004). Predictors of adherence to screening mammography among Korean American women. Prev.Med., 39, 474-481.

Kagay, C. R., Quale, C., \& Smith-Bindman, R. (2006). Screening mammography in the American elderly. Am.J.Prev.Med., 31, 142-149.

Kandula, N. R., Wen, M., Jacobs, E. A., \& Lauderdale, D. S. (2006). Low rates of colorectal, cervical, and breast cancer screening in Asian Americans compared with nonHispanic whites: Cultural influences or access to care? Cancer, 107, 184-192.

Kaplan, R. M., Navarro, A. M., Castro, F. G., Elder, J. P., Mishra, S. I., Hubbell, A. et al. (1996). Increased use of mammography among Hispanic women: baseline results from the NCI Cooperative Group on Cancer Prevention in Hispanic Communities. Am.J.Prev.Med., 12, 467-471.

Kelley, M. A. (2004). Culturally appropriate breast health educational intervention program for African-American women. J.Natl.Black.Nurses Assoc., 15, 36-47.

Kerlikowske, K., Creasman, J., Leung, J. W., Smith-Bindman, R., \& Ernster, V. L. (2005). Differences in screening mammography outcomes among White, Chinese, and Filipino women. Arch.Intern.Med., 165, 1862-1868.

Kernohan, E. E. (1996). Evaluation of a pilot study for breast and cervical cancer screening with Bradford's minority ethnic women; a community development approach, 1991-93. Br.J.Cancer Suppl, 29, S42-S46.

Kiger, H. (2003). Outreach to multiethnic, multicultural, and multilingual women for breast cancer and cervical cancer education and screening: a model using professional and volunteer staffing. Fam.Community Health, 26, 307-318.

Kline, K. N. (2007). Cultural sensitivity and health promotion: assessing breast cancer education pamphlets designed for African American women. Health Commun., 21, 85-96. 
Kreuter, M. W., Holmes, K., Alcaraz, K., Kalesan, B., Rath, S., Richert, M. et al. (2010). Comparing narrative and informational videos to increase mammography in lowincome African American women. Patient.Educ.Couns., 81 Suppl, S6-14.

Kreuter, M. W., Lukwago, S. N., Bucholtz, R. D., Clark, E. M., \& Sanders-Thompson, V. (2003). Achieving cultural appropriateness in health promotion programs: targeted and tailored approaches. Health Educ.Behav., 30, 133-146.

Kreuter, M. W., Sugg-Skinner, C., Holt, C. L., Clark, E. M., Haire-Joshu, D., Fu, Q. et al. (2005). Cultural tailoring for mammography and fruit and vegetable intake among low-income African-American women in urban public health centers. Prev.Med., 41, 53-62.

Lackland, D. T., Dunbar, J. B., Keil, J. E., Knapp, R. G., \& O'Brien, P. H. (1991). Breast cancer screening in a biracial community: the Charleston tricounty experience. South.Med.J., 84, 862-866.

Legler, J., Meissner, H. I., Coyne, C., Breen, N., Chollette, V., \& Rimer, B. K. (2002). The effectiveness of interventions to promote mammography among women with historically lower rates of screening. Cancer Epidemiol.Biomarkers Prev., 11, 59-71.

Luquis, R. R. \& Villanueva Cruz, I. J. (2006). Knowledge, attitudes, and perceptions about breast cancer and breast cancer screening among Hispanic women residing in South Central Pennsylvania. J.Community Health, 31, 25-42.

Madan, A. K., Barden, C. B., Beech, B., Fay, K., Sintich, M., \& Beech, D. J. (2002). Selfreported differences in daily raw vegetable intake by ethnicity in a breast screening program. J.Natl.Med.Assoc., 94, 894-900.

Mandelblatt, J., Kaufman, E., Sheppard, V. B., Pomeroy, J., Kavanaugh, J., Canar, J. et al. (2005). Breast cancer prevention in community clinics: will low-income Latina patients participate in clinical trials? Prev.Med., 40, 611-618.

Mandelblatt, J. S. \& Yabroff, K. R. (1999). Effectiveness of interventions designed to increase mammography use: a meta-analysis of provider-targeted strategies. Cancer Epidemiol.Biomarkers Prev., 8, 759-767.

Maxwell, A. E., Bastani, R., \& Warda, U. S. (2000). Demographic predictors of cancer screening among Filipino and Korean immigrants in the United States. Am.J.Prev.Med., 18, 62-68.

Maxwell, A. E., Jo, A. M., Crespi, C. M., Sudan, M., \& Bastani, R. (2010). Peer navigation improves diagnostic follow-up after breast cancer screening among Korean American women: results of a randomized trial. Cancer Causes Control, 21, 19311940.

McAlister, A. L., Fernandez-Esquer, M. E., Ramirez, A. G., Trevino, F., Gallion, K. J., Villarreal, R. et al. (1995). Community level cancer control in a Texas barrio: Part II-Base-line and preliminary outcome findings. J.Natl.Cancer Inst.Monogr, 123-126.

Meade, C. D., Calvo, A., \& Cuthbertson, D. (2002). Impact of culturally, linguistically, and literacy relevant cancer information among Hispanic farmworker women. J.Cancer Educ., 17, 50-54.

Menon, U., Champion, V., Monahan, P. O., Daggy, J., Hui, S., \& Skinner, C. S. (2007). Health belief model variables as predictors of progression in stage of mammography adoption. Am.J.Health Promot., 21, 255-261. 
Michielutte R, Sharp PC, KL Foley, JG Spangler, ED Paskett, \& LD Case. (2005). Intervention to increase screening mammography among women 65 and older. Health Education Research 20[2], 149-162.

Mishra, S. I., Bastani, R., Crespi, C. M., Chang, L. C., Luce, P. H., \& Baquet, C. R. (2007). Results of a randomized trial to increase mammogram usage among Samoan women. Cancer Epidemiol.Biomarkers Prev., 16, 2594-2604.

Navarro, A. M., Senn, K. L., Kaplan, R. M., McNicholas, L., Campo, M. C., \& Roppe, B. (1995). Por La Vida intervention model for cancer prevention in Latinas. J.Natl.Cancer Inst.Monogr, 137-145.

Newman, D. H. (2010). Screening for breast and prostate cancers: moving toward transparency. J.Natl.Cancer Inst., 102, 1008-1011.

Nguyen, T., Vo, P. H., McPhee, S. J., \& Jenkins, C. N. (2001). Promoting early detection of breast cancer among Vietnamese-American women. Results of a controlled trial. Cancer, 91, 267-273.

Nguyen, T. T., Le, G., Nguyen, T., Le, K., Lai, K., Gildengorin, G. et al. (2009). Breast cancer screening among Vietnamese Americans: a randomized controlled trial of lay health worker outreach. Am.J.Prev.Med., 37, 306-313.

Nguyen, T. T., McPhee, S. J., Gildengorin, G., Nguyen, T., Wong, C., Lai, K. Q. et al. (2006). Papanicolaou testing among Vietnamese Americans: results of a multifaceted intervention. Am.J.Prev.Med., 31, 1-9.

Nguyen, T. T., McPhee, S. J., Nguyen, T., Lam, T., \& Mock, J. (2002). Predictors of cervical Pap smear screening awareness, intention, and receipt among VietnameseAmerican women. Am.J.Prev.Med., 23, 207-214.

O'Malley, A. S., Forrest, C. B., \& Mandelblatt, J. (2002). Adherence of low-income women to cancer screening recommendations. J.Gen.Intern.Med., 17, 144-154.

Oetzel, J., De, V. F., Ginossar, T., \& Sanchez, C. (2007). Hispanic women's preferences for breast health information: subjective cultural influences on source, message, and channel. Health Commun., 21, 223-233.

Orians, C. E., Erb, J., Kenyon, K. L., Lantz, P. M., Liebow, E. B., Joe, J. R. et al. (2004). Public education strategies for delivering breast and cervical cancer screening in American Indian and Alaska Native populations. J.Public Health Manag.Pract., 10, 46-53.

Paskett, E. D., Tatum, C., Rushing, J., Michielutte, R., Bell, R., Foley, K. L. et al. (2004). Racial differences in knowledge, attitudes, and cancer screening practices among a triracial rural population. Cancer, 101, 2650-2659.

Peek, M. E. \& Han, J. H. (2004). Disparities in screening mammography. Current status, interventions and implications. J.Gen.Intern.Med., 19, 184-194.

Powe, B. D. \& Cooper, D. L. (2008). Self-reported cancer screening rates versus medical record documentation: incongruence, specificity, and sensitivity for African American women. Oncol.Nurs.Forum, 35, 199-204.

Purc-Stephenson, R. J. \& Gorey, K. M. (2008). Lower adherence to screening mammography guidelines among ethnic minority women in America: a meta-analytic review. Prev.Med., 46, 479-488.

Qureshi, M., Thacker, H. L., Litaker, D. G., \& Kippes, C. (2000). Differences in breast cancer screening rates: an issue of ethnicity or socioeconomics? J.Womens Health Gend.Based.Med., 9, 1025-1031. 
Ramirez, A. G., Talavera, G. A., Villarreal, R., Suarez, L., McAlister, A., Trapido, E. et al. $(2000)$. Breast cancer screening in regional Hispanic populations. Health Educ.Res., $15,559-568$.

Rawl, S. M., Champion, V. L., Menon, U., \& Foster, J. L. (2000). The impact of age and race on mammography practices. Health Care Women Int., 21, 583-597.

Remennick, L. (2006). The challenge of early breast cancer detection among immigrant and minority women in multicultural societies. Breast J., 12 Suppl 1, S103-S110.

Roetzheim, R. G., Vandurme, D. J., Brownlee, H. J., Herold, A. H., Pamies, R. J., Woodard, L. et al. (1992). Reverse targeting in a media-promoted breast cancer screening project. Cancer, 70, 1152-1158.

Russell, K. M., Champion, V. L., Monahan, P. O., Millon-Underwood, S., Zhao, Q., Spacey, N. et al. (2010). Randomized trial of a lay health advisor and computer intervention to increase mammography screening in African American women. Cancer Epidemiol.Biomarkers Prev., 19, 201-210.

Sadler, G. R., Hung, J., Beerman, P. R., Chen, M., Chow, J., \& Chan, N. (2009). Then and now: comparison of baseline breast cancer screening rates at 2 time intervals. J.Cancer Educ., 24, 4-9.

Saint-Germain, M. A. \& Longman, A. J. (1993). Breast cancer screening among older Hispanic women: knowledge, attitudes, and practices. Health Educ.Q., 20, 539-553.

Samsudeen, B. S., Douglas, A., \& Bhopal, R. S. (2011). Challenges in recruiting South Asians into prevention trials: health professional and community recruiters' perceptions on the PODOSA trial. Public Health, 125, 201-209.

Sassi, F., Luft, H. S., \& Guadagnoli, E. (2006). Reducing racial/ethnic disparities in female breast cancer: screening rates and stage at diagnosis. Am.J.Public Health, 96, 21652172.

Sauaia, A., Min, S. J., Lack, D., Apodaca, C., Osuna, D., Stowe, A. et al. (2007). Church-based breast cancer screening education: impact of two approaches on Latinas enrolled in public and private health insurance plans. Prev.Chronic.Dis., 4, A99.

Selvin, E. \& Brett, K. M. (2003). Breast and cervical cancer screening: sociodemographic predictors among White, Black, and Hispanic women. Am.J.Public Health, 93, 618623.

Shin, H. R., Joubert, C., Boniol, M., Hery, C., Ahn, S. H., Won, Y. J. et al. (2010). Recent trends and patterns in breast cancer incidence among Eastern and Southeastern Asian women. Cancer Causes Control, 21, 1777-1785.

Skaer, T. L., Robison, L. M., Sclar, D. A., \& Harding, G. H. (1996). Cancer-screening determinants among Hispanic women using migrant health clinics. J.Health Care Poor Underserved, 7, 338-354.

Skinner, C. S., Strecher, V. J., \& Hospers, H. (1994). Physicians' recommendations for mammography: do tailored messages make a difference? Am.J.Public Health, 84, 4349.

Strzelczyk, J. J. \& Dignan, M. B. (2002). Disparities in adherence to recommended followup on screening mammography: interaction of sociodemographic factors. Ethn.Dis., 12, 77-86.

Suarez, L. \& Pulley, L. (1995). Comparing acculturation scales and their relationship to cancer screening among older Mexican-American women. J.Natl.Cancer Inst.Monogr, 41-47. 
Suh, E. E. (2008). The sociocultural context of breast cancer screening among Korean immigrant women. Cancer Nurs., 31, E1-10.

Sung, J. F., Blumenthal, D. S., Coates, R. J., Williams, J. E., Alema-Mensah, E., \& Liff, J. M. (Sung et al., 1997). Effect of a cancer screening intervention conducted by lay health workers among inner-city women. Am.J.Prev.Med., 13, 51-57.

Tejeda, S., Thompson, B., Coronado, G. D., Heagerty, P. J., \& Martin, D. P. (2009). Celebremos la Salud: a community-based intervention for Hispanic and nonHispanic white women living in a rural area. J.Community Health, 34, 47-55.

Trock, B., Rimer, B. K., King, E., Balshem, A., Cristinzio, C. S., \& Engstrom, P. F. (1993). Impact of an HMO-based intervention to increase mammography utilization. Cancer Epidemiol.Biomarkers Prev., 2, 151-156.

Tu, S. P., Jackson, S. L., Yasui, Y., Deschamps, M., Hislop, T. G., \& Taylor, V. M. (2005). Cancer preventive screening: a cross-border comparison of United States and Canadian Chinese women. Prev.Med., 41, 36-46.

U.S.Department of Health and Human ServicesOffice of Minority Health (2001). National Standards for Culturally and LinguisticallyAppropriate Services in Health Care Rockville, MD: IQ Solutions, Inc.

Underwood SM \& M Canales. (2005). Expanding and strengthening research focused on breast cancer in African American women: building upon what is known. JOCEPS: The Journal of Chi Eta Phi Sorority 51[1], 2-24. 8-8-2011.

Valdez, A., Banerjee, K., Ackerson, L., \& Fernandez, M. (2002). A multimedia breast cancer education intervention for low-income Latinas. J.Community Health, 27, 33-51.

Vernon, S. W., McQueen, A., Tiro, J. A., \& del Junco, D. J. (2010). Interventions to promote repeat breast cancer screening with mammography: a systematic review and metaanalysis. J.Natl.Cancer Inst., 102, 1023-1039.

Watts, T., Merrell, J., Murphy, F., \& Williams, A. (2004). Breast health information needs of women from minority ethnic groups. J.Adv.Nurs., 47, 526-535.

Wee, C. C., McCarthy, E. P., Davis, R. B., \& Phillips, R. S. (2004). Obesity and breast cancer screening. J.Gen.Intern.Med., 19, 324-331.

Wells, K. J. \& Roetzheim, R. G. (2007). Health disparities in receipt of screening mammography in Latinas: a critical review of recent literature. Cancer Control, 14, 369-379.

Welsh, A. L., Sauaia, A., Jacobellis, J., Min, S. J., \& Byers, T. (2005). The effect of two churchbased interventions on breast cancer screening rates among Medicaid-insured Latinas. Prev.Chronic.Dis., 2, A07.

West, D. S., Greene, P., Pulley, L., Kratt, P., Gore, S., Weiss, H. et al. (2004). Stepped-care, community clinic interventions to promote mammography use among low-income rural African American women. Health Educ.Behav., 31, 29S-44S.

Williams, K. P., Mabiso, A., Lo, Y. J., \& Penner, L. A. (2010). Mammography screening trends: the perspective of African American women born pre/post World War II. J.Natl.Med.Assoc., 102, 452-460.

Wu, L., Colby, E., Iongi-Filiaga, A., \& Maskarinec, G. G. (2010). American Samoan women's health: experiences and attitudes toward breast and cervical cancer screening. Hawaii Medical Journal, 69, Suppl-20.

Yang, R., Cheung, M. C., Franceschi, D., Hurley, J., Huang, Y., Livingstone, A. S. et al. (2009). African-American and low-socioeconomic status patients have a worse prognosis 
for invasive ductal and lobular breast carcinoma: do screening criteria need to change? J.Am.Coll.Surg., 208, 853-868.

Yankaskas, B. C. \& Gill, K. S. (2005). Diagnostic mammography performance and race: outcomes in Black and White women. Cancer, 104, 2671-2681.

Young, R. F., Waller, J. B., Jr., \& Smitherman, H. (2002). A breast cancer education and onsite screening intervention for unscreened African American women. J.Cancer Educ., 17, 231-236.

Zhu, K., Hunter, S., Bernard, L. J., Payne-Wilks, K., Roland, C. L., Elam, L. C. et al. (2002). An intervention study on screening for breast cancer among single African-American women aged 65 and older. Prev.Med., 34, 536-545. 


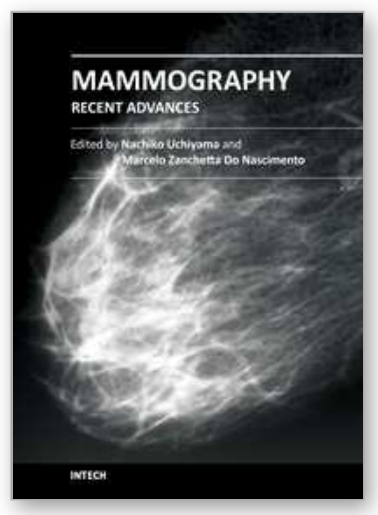

\author{
Mammography - Recent Advances \\ Edited by Dr. Nachiko Uchiyama
}

ISBN 978-953-51-0285-4

Hard cover, 418 pages

Publisher InTech

Published online 16, March, 2012

Published in print edition March, 2012

In this volume, the topics are constructed from a variety of contents: the bases of mammography systems, optimization of screening mammography with reference to evidence-based research, new technologies of image acquisition and its surrounding systems, and case reports with reference to up-to-date multimodality images of breast cancer. Mammography has been lagged in the transition to digital imaging systems because of the necessity of high resolution for diagnosis. However, in the past ten years, technical improvement has resolved the difficulties and boosted new diagnostic systems. We hope that the reader will learn the essentials of mammography and will be forward-looking for the new technologies. We want to express our sincere gratitude and appreciation?to all the co-authors who have contributed their work to this volume.

\title{
How to reference
}

In order to correctly reference this scholarly work, feel free to copy and paste the following:

Mabel E. Caban and Beverley Adams-Huet (2012). Meta-Analysis: Culturally Sensitive Education and Mammography Uptake of Minority Women, Mammography - Recent Advances, Dr. Nachiko Uchiyama (Ed.), ISBN: 978-953-51-0285-4, InTech, Available from: http://www.intechopen.com/books/mammography-recentadvances/meta-analysis-culturally-sensitive-education-and-screening-mammography-among-minority-women

\section{INTECH}

open science | open minds

\section{InTech Europe}

University Campus STeP Ri

Slavka Krautzeka 83/A

51000 Rijeka, Croatia

Phone: +385 (51) 770447

Fax: +385 (51) 686166

www.intechopen.com

\section{InTech China}

Unit 405, Office Block, Hotel Equatorial Shanghai

No.65, Yan An Road (West), Shanghai, 200040, China

中国上海市延安西路65号上海国际贵都大饭店办公楼 405 单元

Phone: +86-21-62489820

Fax: +86-21-62489821 
(C) 2012 The Author(s). Licensee IntechOpen. This is an open access article distributed under the terms of the Creative Commons Attribution 3.0 License, which permits unrestricted use, distribution, and reproduction in any medium, provided the original work is properly cited. 